\title{
Modified Pro-Self Pain Control to Increase Activity in Patients with Colorectal Cancer
}

\author{
Khoirunnisa' Munawaroh ${ }^{1}$, Untung Sujianto ${ }^{2}$, Mardiyono $^{3}$ \\ ${ }^{1}$ Student of Master Program in Nursing, Diponegoro University, Indonesia \\ ${ }^{2}$ Department of Nursing, Faculty of Medicine, Diponegoro University, Indonesia \\ ${ }^{3}$ Department of Nursing, Health Polytechnic of Semarang, Indonesia \\ Corresponding Author: Untung Sujianto (untung71@yahoo.co.id)
}

\begin{abstract}
Background: Barriers to performing activities of daily living are common complaints of patients with cancer. One of the factors causing these barriers is pain. A modified pro-self pain control is a method used to enhance the patients' ability to cope with pain to increase their activity.

Purpose: This study aimed to evaluate the modified pro-self pain control to increase activity in patients with colorectal cancer undergoing chemotherapy.

Methods: The present study employed an experimental design. Patients with colorectal cancer undergoing chemotherapy were randomly assigned to the intervention group $(n=24)$ and the control group $(n=24)$. The patients in the control group were given a standard hospital intervention, while the patients in the intervention group were given the modified pro-self pain control for nine days. The data were collected using the instrument of KATZ index and analyzed using the independent t-test.

Results: The result of this study showed that there was a higher increase of activity among the patients in the intervention group than in the control group. Independent $t$ test showed that there was a significant difference between the intervention group and the control group $(\mathrm{p}=0.00)$.

Conclusion: The modified pro-self pain control was found more effective to increase the activity in patients with colorectal cancer undergoing chemotherapy than that of the standard hospital intervention.
\end{abstract}

Keywords: Activity; pro-self pain control; colorectal cancer

\section{BACKGROUND}

Colorectal cancer is a disease caused by the abnormal increase and growth of cells in the body, particularly in the lining of the colon and rectum. The World Health Organization (WHO) stated that the incidence of cancer increased from 12.7 million cases per year in 2008 to 14.1 million cases in 2012. The case of colorectal cancer was ranked third in the world (WHO, 2012). The signs and symptoms of this cancer, among others, include abdominal pain, changes in fecal elimination pattern, the presence of blood in stool, and the existence of mass in the abdominal area (Keslen, 2008). 
Chemotherapy is one type of cancer management administered by the provision of the cytostatic drugs to inhibit and kill the cells in the body, which actively metastasize. The type of chemotherapy drugs for colorectal cancer includes the 5-flurourasil, leucovorin, oxaliplatin, capecitabine, and avastin, or a combination of these drugs. The drugs give some side effects such as pain, fatigue and muscle weakness (Keslen 2008).

A study by Wagner \& Cella (2004) showed that pain serves as a factor affecting the occurrence of fatigue, which impacts on one's ability to undertake his activity of daily living. Based on the data from the cancer patients undergoing chemotherapy in Italy, $50 \%$ of patients reported that the pain affected their activities of daily living (Di Maio et al., 2004). Furthermore, Lowery et al. (2013) stated that increased pain in patients with colorectal cancer undergoing chemotherapy is caused by a number of factors; one of which is the physical activity such as climbing stairs or walking, lifting, overextending, standing, urination/defecation, sleep and some other things like diet, stress, and weather. If the patients are unable to perform the daily activities, they can have a deterioration in their quality of life (Widyaningsih, 2013)

There are several interventions to promote the activities such as jogging or aerobic exercises. A systematic review mentioned that the physical activity might provide a significant effect on the increase in someone's activity (Speck, Courneya, Masse, Duval, \& Schmitz, 2010). The performed exercises are aimed to increase the muscle strength but have not been able to reduce the pain.

In reducing pain in patients with cancer, there are pharmacological and nonpharmacological therapies which can be administered based on the level of pain. The non-pharmacological therapy includes psycho-education, massage, acupuncture, music, spiritual and emotional freedom technique (Hakam, Yetti, \& Hariyati, 2009; Li et al., 2011; Lian, Pan, Zhou, \& Zhang, 2014; Rustøen, Valeberg, \& Kolstad, 2012).

In the management of pain, there are several constraints, such as the intervention can only be done by the health workers, and the patients are unable to detect pain and perform the pain management independently at home (Jacobsen, Moldrup, Christrup, 2009). It is necessary to develop an alternative intervention which can be done by patients independently. A modified pro-self pain control is such a method to enhance the patients' ability to cope with pain to increase their activity. There were no previous studies conducted a modified pro-self pain control on patients with colorectal cancer undergoing chemotherapy. Therefore, this study is urgently needed.

\section{PURPOSE}

This study was aimed at evaluating the modified pro-self pain control to increase activity in patients with colorectal cancer undergoing chemotherapy.

\section{METHODS}

This study employed an experimental research design with a randomized control trial. It was reviewed and approved by the health research ethics committee of Diponegoro University \& the hospital in Semarang where this study took place. The study was conducted in November 2016 to January 2017. The samples were determined by a 
simple random sampling, which resulted in 24 participants in the intervention group and 24 participants in the control group. A written informed consent was obtained from all participants before their participation in this study. The inclusion criteria included the patients with colorectal cancer undergoing chemotherapy, were of cancer stage of 3-4, the age of 18-60 years old, pain scale of $\geq 3$, activity scale of $\geq 1$, and were able to write. Meanwhile, the exclusion criteria included the patients who received additional radiotherapy and experienced a total dependence. The data were collected by using the KATZ index with a range score of $0-6$. This instrument showed a Cronbach alpha of 0.88 for its reliability and could be easily and independently used by both young and old patients (Mystakidou, Parpa, Tsilika, Panagiotou I, et al., 2013).

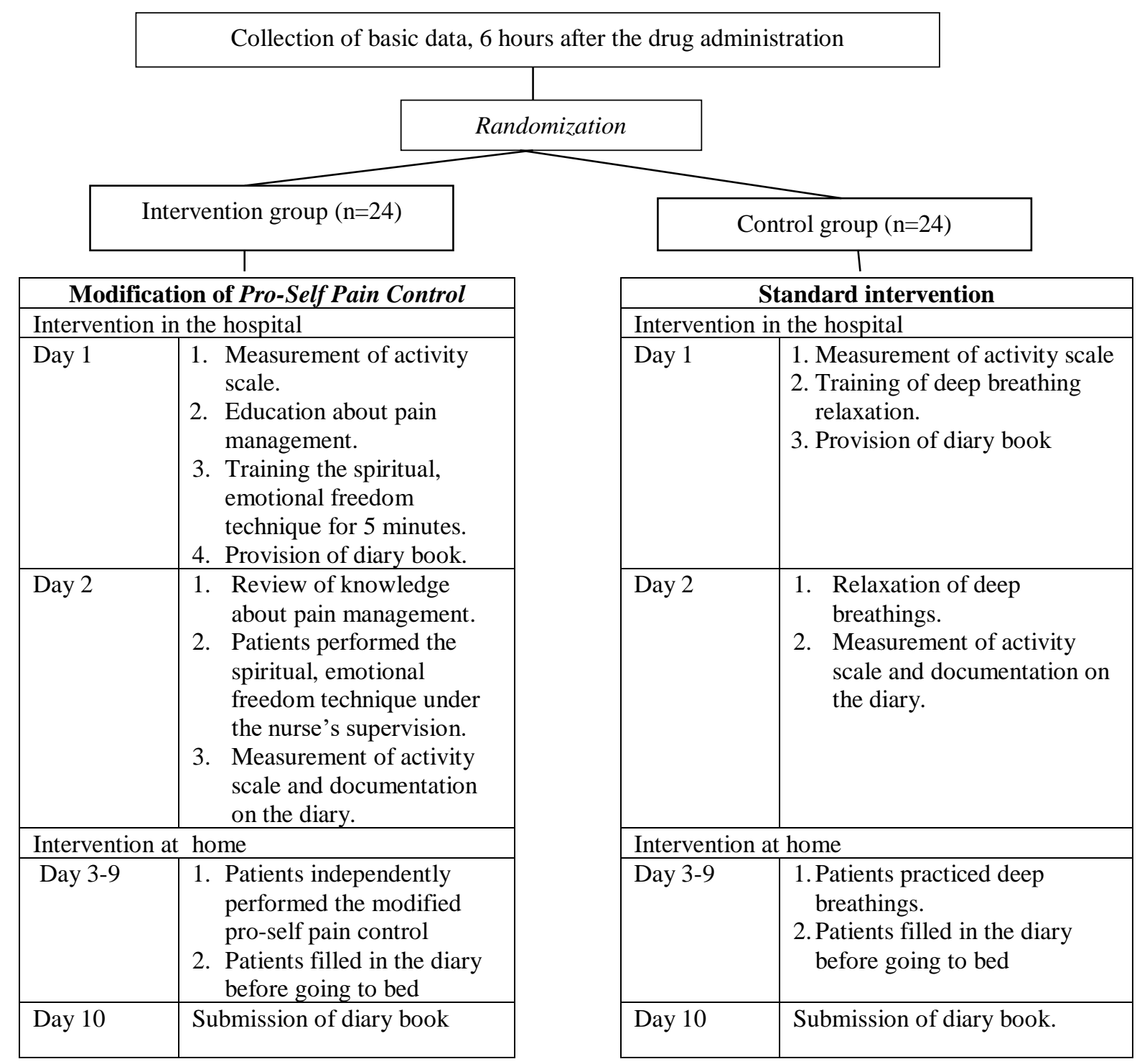

Figure 1. Research procedure in the intervention group and the control group

The modified pro-self pain control is a development of the pro-self pain control. This intervention consists of the monitoring of pain and activity through the diary book, the spiritual, emotional freedom technique (SEFT), the provision of health education and 
drug management. In this intervention, the patient plays a role in handling the activity problems independently. The SEFT which uses a tapping on certain meridian points provides benefits to improve the physical abilities of the patients (Brattberg, 2008). The intervention was given for nine days for each participant. Figure 1 illustrates the research procedure for the intervention group and control group.

The researchers used the paired t-test to compare and analyze the results in all groups. In addition, the independent t-test was used to investigate the mean differences between the intervention group and the control group.

\section{RESULTS}

From November 2016 to January 2017, 48 participants were involved in the study. The characteristics of the participants were presented in Table 1. The average age of participants in the intervention group was 47.62 SD 11.79, and in the control group was 49.58 SD 9.79. The male participants were 26 , and the rest were female. The diagnosis of these patients included ca colon, ca rectum, ca colon metas hepar, ca recti metas hepar and ca colorectal. The most participants were undergoing the first cycle of chemotherapy.

Table 1. Characteristics of participants $(n=48)$

\begin{tabular}{lccc}
\hline \multicolumn{1}{c}{ Characteristics } & $\begin{array}{c}\text { Intervention group } \\
\mathrm{n}(\%) \text { or mean (SD) }\end{array}$ & $\begin{array}{c}\text { Control group } \\
\mathrm{n}(\%) \text { or mean }(\mathrm{SD})\end{array}$ & $\mathrm{p}$-value \\
\hline Age & $47.62(11.79)$ & $49.58(9.79)$ & 0.246 \\
Mean (SD) & $8(33.33)$ & $6(25.00)$ & \\
18-45 & $16(67.67)$ & $18(75.00)$ & 0.422 \\
46-60 & & & \\
Gender & $12(50.00)$ & $14(58.30)$ & \\
Male & $12(50.00)$ & $10(47.70)$ & 0.129 \\
Female & & & \\
Diagnosis & $11(45.80)$ & $11(45.80)$ & \\
ca colon & $9(37.50)$ & $11(45.80)$ & \\
ca rectum & $0(0.00)$ & $2(8.30)$ & \\
ca colon metas hepar & $2(8.33)$ & $0(0.00)$ & \\
ca recti metas hepar & $2(8.33)$ & $0(0.00)$ & \\
ca colorectal & & & \\
Cycle of chemotherapy & $5(20.83)$ & $5(20.83)$ & \\
cycle 1 & $2(8.33)$ & $2(8.33)$ & \\
cycle 2 & $2(8.33)$ & $2(8.33)$ & \\
cycle 3 & $1(4.17)$ & $1(4.17)$ & \\
cycle 4 & $2(8.33)$ & $2(8.33)$ & \\
cycle 5 & $2(8.33)$ & $2(8.33)$ & \\
cycle 6 & $2(8.33)$ & $2(8.33)$ & \\
cycle 7 & $2(8.33)$ & $2(8.33)$ & \\
cycle 8 & $1(4.17)$ & $1(4.17)$ & \\
cycle 9 & $1(4,17)$ & $1(4,17)$ & \\
cycle 10 & $2(8.33)$ & $2(8.33)$ & \\
cycle 11 & $2(8.33)$ & $2(8.33)$ & \\
cycle 12 & & & \\
\hline
\end{tabular}




\section{Activity Scale}

The results of analysis of the effects of the modified pro-self pain control were presented in Table 3. From day 1 to day 9 in the intervention group, the mean value of activity increased from $4.29(\mathrm{SD}=1.30)$ to $5.17(\mathrm{SD}=0.72)$. Meanwhile, in the control group, the mean increased from $4.62(\mathrm{SD}=1.06)$ to $4.92(\mathrm{SD}=1.05)$. The profile of this increased activity is presented in Figure 2.

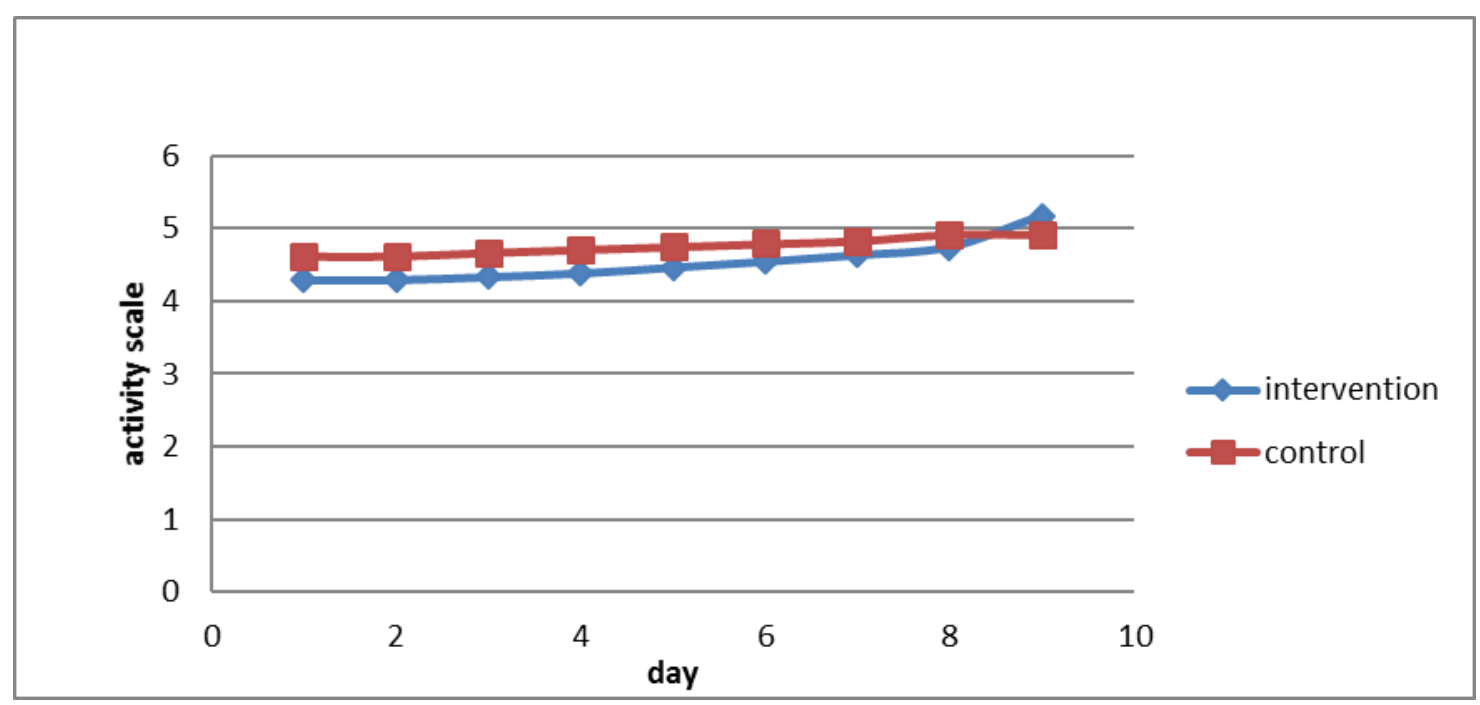

Figure 2. Profile of activity in the intervention and control group

The result of the within-group analysis for nine days in the intervention group showed a p-value of $<0.001$. The effect of modified pro-self pain control was shown on day 9 $(p=0.05)$. In the control group, the significant $p$-value was 0.05 . The analysis for each day showed the $\mathrm{p}$-value $>0.05$.

Table 2. Effects of modified pro-self pain control in the intervention group and the control group $(n=48)$

\begin{tabular}{lcccccccc}
\hline & \multicolumn{3}{c}{$\begin{array}{c}\text { Intervention Group } \\
(\mathrm{n}=24)\end{array}$} & \multicolumn{5}{c}{$\begin{array}{c}\text { Control Group } \\
(\mathrm{n}=24)\end{array}$} \\
\cline { 2 - 9 } Day & Mean & SD & $\mathrm{t}$ & $\mathrm{p}$ & Mean & $\mathrm{SD}$ & $\mathrm{t}$ & $\mathrm{p}$ \\
\hline Day 1 & 4.29 & 1.30 & -3.23 & $<0.0$ & 4.62 & 1.06 & -2.29 & 0.05 \\
Day 9 & 5.17 & 0.72 & & 01 & 4.92 & 1.05 & & \\
& & & & & & & & \\
Day 1 & 4.29 & 1.30 & 0.00 & 1.00 & 4.62 & 1,05 & 0.00 & 1.00 \\
Day 2 & 4.29 & 1.19 & & & 4.62 & 1.09 & & \\
Day 2 & 4.29 & 1.19 & -0.21 & 0.83 & 4.62 & 1.09 & -0.37 & 0.71 \\
Day 3 & 4.33 & 1.23 & & & 4.67 & 1.09 & & \\
& & & & & & & & \\
Day 3 & 4.33 & 1.23 & -0.57 & 0.56 & 4,67 & 1.09 & -0.37 & 0.71 \\
Day 4 & 4.38 & 1.05 & & & 4.71 & 1.04 & & \\
Day 4 & 4.38 & 1.05 & -0.49 & 0.63 & 4.71 & 1.04 & -0.44 & 0.66 \\
Day 5 & 4.46 & 1.25 & & & 4.75 & 1.07 & & \\
\hline
\end{tabular}




\begin{tabular}{lcccccccc}
\hline & \multicolumn{3}{c}{$\begin{array}{c}\text { Intervention Group } \\
(\mathrm{n}=24)\end{array}$} & & \multicolumn{5}{c}{$\begin{array}{c}\text { Ontrol Group } \\
(\mathrm{n}=24)\end{array}$} \\
\cline { 2 - 9 } Day & Mean & $\mathrm{SD}$ & $\mathrm{t}$ & $\mathrm{p}$ & Mean & $\mathrm{SD}$ & $\mathrm{t}$ & $\mathrm{p}$ \\
\hline Day 5 & 4.46 & 1.25 & -0.49 & 0.63 & 4.75 & 1.07 & -0.44 & 0.66 \\
Day 6 & 4.54 & 1.02 & & & 4.79 & 0.98 & & \\
Day 6 & & & -1.44 & 0.16 & 4.79 & 0.98 & -0.44 & 0.66 \\
Day 7 & & & & & 4.83 & 1.01 & & \\
Day 7 & 4.63 & 0.92 & -1.54 & 0.13 & 4.83 & 1.01 & -1.00 & 0.33 \\
Day 8 & 4.75 & 1.03 & & & 4.92 & 0.97 & & \\
Day 8 & 4.75 & 1.03 & -2.09 & 0.05 & 4.92 & 0.97 & 0.00 & 1.00 \\
Day 9 & 5.17 & 0.76 & & & 4.92 & 1.05 & & \\
\hline
\end{tabular}

A further statistical test was performed to see the difference between the intervention group and the control group by using the mean difference between the pre-test and the post-test. The result of the independent t-test is depicted in Table 3.

Table 3. Analysis of mean difference of activities after the implementation of modified pro-self pain control in the intervention group and control group

\begin{tabular}{lcccc}
\hline \multicolumn{1}{c}{ Groups } & Mean & SD & $\mathrm{t}$ & $\mathrm{p}$ \\
\hline Intervention & 0.88 & 0.67 & -3.10 & $<0.001$ \\
Control & 0.30 & 0.62 & & \\
\hline
\end{tabular}

The results of the between-group analysis for nine days in the intervention group and control group showed a p-value $<0.001$. It indicated that the modified pro-self pain control was found more effective to increase the activity in patients with colorectal cancer undergoing chemotherapy than the standard hospital intervention.

\section{DISCUSSION}

The activities of daily living (ADL) are a self-care task in one's everyday life. These activities include bathing, dressing, control of bowel movement or urination, use of the toilet, and the moving activity, which are measured every 24 hours. The results of the pre-test on the participant activity showed a value of 4.29 in the intervention group and 4.62 in the control group. A decreased activity value in patients with cancer was caused by several factors such as the stage of cancer and the side effects of therapy. A study by Quach, Sanoff, Williams, Lyons, et al. (2014) stated that an increase in the stage of cancer caused some disturbances in the other organs that impacted the metabolism. Emblom \& Cambell (2011) found that the activity value of patients with colorectal cancer undergoing therapy decreased during the therapy and bounced back after the therapy ended. Chemotherapy and radiotherapy can cause decreased muscle strength so that the patients can have troubles of performing their everyday activities independently (Mustian, Sprod, Peppone, \& Mohile, 2013).

The present findings showed differences in the activity of the participants in both groups. In contrast to a study by Brattberg (2008), the increase of activity in this study 
was still minimal. This was possible since Brattberg (2008) carried out the study for eight weeks. Similarly, Speck, Courneya, Mâsse, Duval, \& Schmitz (2010) also indicated an increase of activity in patients after five weeks of intervention.

A previous study by Speck, Courneya, Mâsse, Duval, \& Schmitz, (2010) showed that the patients' activity could be increased by walking, practicing aerobics, and progressive resistance training. These activities are focused on increasing muscle strength and reducing fatigue in the cancer patient. Regarding activity, some factors are found influential; one of which is pain (Di Maio, 2004). Pain serves as a factor affecting the occurrence of fatigue, which impacts on activity (Wagner \& Cella, 2004). In this study, the main focus to address the problem of activity is to cope with pain independently.

The modified pro-self pain control was evident to increase self-management related to pain and activity experienced by patients while undergoing chemotherapy. The patients were trained to assess the pain and ability to perform daily activity and were requested to record it in the diary. Therefore, it would be easier for the patients to communicate with doctors or nurses about their pain and activity disturbance that they experienced. The provision of health education increased the knowledge of the patients about the management of pain and activity (Adam, Bond, \& Marchie, 2015; Ling, Lui, and So, 2011). In this study, the education was promoted by using a booklet so that the patients could read it when they were at home. Furthermore, the patients were also given the spiritual and emotional freedom technique (SEFT) and were trained to be able to do it independently at home. On the time of tapping step, the patients focused on the acceptance of pain and the disruption of activity. The tapping performed on certain meridian points could reduce the pain due to the production of endorphins and improve the muscle strength in patients (Brattberg, 2008).

Modified pro-self pain control could increase activity, but it was still minimal. The sample size in this study was under 50. Therefore, it is important for the next studies to involve a larger number of participants. Furthermore, the period for intervention could be expanded to 2 weeks so it could show the effectiveness of the intervention in each chemotherapy cycle.

\section{CONCLUSION}

Based on the present findings, it was concluded that the modified pro-self pain control could increase the activity of patients with colorectal cancer undergoing chemotherapy. The modified pro-self pain control can be used as an alternative to nursing intervention, particularly for the management of pain so as to increase the activity in patients with colorectal cancer. Nurses can educate the patients about the modified pro-self pain control since the patient can do this intervention independently.

\section{REFERENCES}

Adam, R., Bond, C., \& Murchie, P. (2015). Educational interventions for cancer pain. A systematic review of systematic reviews with nested narrative review of randomized controlled trials. Patient Education and Counseling, 98(3), 269-282. http://doi.org/10.1016/j.pec.2014.11.003 
Brattberg, G. (2008). Self-administered EFT (Emotional Freedom Techniques) in Individuals With Fibromyalgia: A Randomized Trial. Integrative Medicine, 7(4), 30-36.

Di Maio, M., Gridelli, C., Gallo, C., Manzione, L., Brancaccio, L., Barbera, S., ... Perrone, F. (2004). Prevalence and management of pain in Italian patients with advanced non-small-cell lung cancer. British Journal of Cancer, 90(12), 2288-96. http://doi.org/10.1038/sj.bjc.6601810

Emblom, A., \& Cambell, K. (2011). Level of physical, leisure, and daily living activities in cancer patients undergoing radiotherapy: which patients will need additional support to restore activity level after end of therapy? In Cancer Science \& Therapy (p. 7).

Hakam, M., Yetti, K., \& Hariyati, T. S. (2009). Intervensi Spiritual Emotional Freedom Technique Untuk Mengurangi Rasa Nyeri Pada Pasien Kanker [Intervention of Spiritual Emotional Freedom Technique to Decrease Pain in Patients with Cancer]. Makara Kesehatan, 13(2), 91-95.

Institute, national cancer. (n.d.). NCI Dictionary of Cancer Terms. Retrieved March 14, 2016, from http://www.cancer.gov/publications/dictionaries/cancerterms?cdrid $=430401$

Jacobsen R, Moldrup C, Christrup L, S. P. (2009). Patient-related barriers to cancer pain management: a systematic exploratory review. Scan Inavianjournal Caring Science, 23, 190-208.

Keslen, D. (2008). Principles and Practice of Gastrointestinal Oncology (second). Philadelphia: Lippincott William and Wilkins.

Li, X.-M., Yan, H., Zhou, K.-N., Dang, S.-N., Wang, D.-L., \& Zhang, Y.-P. (2011). Effects of music therapy on pain among female breast cancer patients after radical mastectomy: results from a randomized controlled trial. Breast Cancer Research and Treatment, 128(2), 411-419. http://doi.org/10.1007/s10549-011-1533-z

Lian, W.-L., Pan, M., Zhou, D., \& Zhang, Z. (2014). Effectiveness of acupuncture for palliative care in cancer patients: a systematic review. Chinese Journal of Integrative Medicine, 20(2), 136-147. http://doi.org/10.1007/s11655-013-1439-1

Ling, C., Lui, L. Y. Y., \& So, W. K. W. (2011). Do educational interventions improve cancer patients' quality of life and reduce pain intensity? Quantitative systematic review. $J$ Adv Nurs, 68(3):511-20. http://doi.org/10.1111/j.13652648.2011.05841.x

Lowery, A. E., Starr, T., Dhingra, L. K., Rogak, L., Hamrick-price, J. R., Farberov, M., ... Passik, S. D. (2013). Frequency, Characteristics, and Correlates of Pain in a Pilot Study of Colorectal Cancer Survivors 1 - 10 Years Post-Treatment. Pain Medicine, 14, 1673-1680.

Mustian, K. M., Sprod, L. K., Peppone, L. J., \& Mohile, S. (2013). Exercise Recommendations for Cancer-Related Fatigue, Cognitive Impairment, Sleep problems, Depression, Pain, Anxiety, and Physical Dysfunction: A Review. Oncol Hematol Rev, 8(2), 81-88.

Mystakidou K1, Parpa E, Tsilika E, Panagiotou I, Roumeliotou A, Symeonidi M, Galanos A, K. I. (2013). Evaluation of instrumental activities of daily living in Greek patients with advanced cancer. Int J Rehabil Res, 36, 75-80.

Quach, C., Sanoff, H., Williams, G., Lyons, J., \& Reeve, B. (2014). Impact of Colorectal Cancer on Activities of Daily Living and Depression Risk Among 
Older Americans. Value in Health, A1-A295.

Rustøen, T., Valeberg, B. T., \& Kolstad, E. (2012). The Pro-Self Ó Pain Control Program Improves Patients ' Knowledge of Cancer Pain Management. Journal of Pain and Symptom Management, 44(3), 321-330. http://doi.org/10.1016/j.jpainsymman.2011.09.015

Society, A. C. (2016). Colorectal Cancer Guide: How is colorectal cancer stage? Last. Retrieved from http://www.cancer.org/cancer/colonandrectumcancer/

detailedguide/colorectal-cancerstaged

Speck, R. M., Courneya, K. S., Mâsse, L. C., Duval, S., \& Schmitz, K. H. (2010). An update of controlled physical activity trials in cancer survivors: a systematic review and meta-analysis. Cancer Surviv, 87-100. http://doi.org/10.1007/s11764009-0110-5

Wagner, L. I., \& Cella, D. (2004). Fatigue and cancer: causes, prevalence and treatment approaches. British Journal of Cancer, 91(5), 822-8. http://doi.org/10.1038/sj.bjc.6602012

WHO. (2012). Latest world cancer statistics. Retrieved May 15, 2016, from www.iarc.fr/en/media-centre/pr/2013/pdfs/pr223_E.pdf

Widyaningsih, S. (2013). A Survey of Symptom Experience, Symptom Management and Quality of Life of Indonesian Patient With Advance Cancer. Prince of Songkla University. 